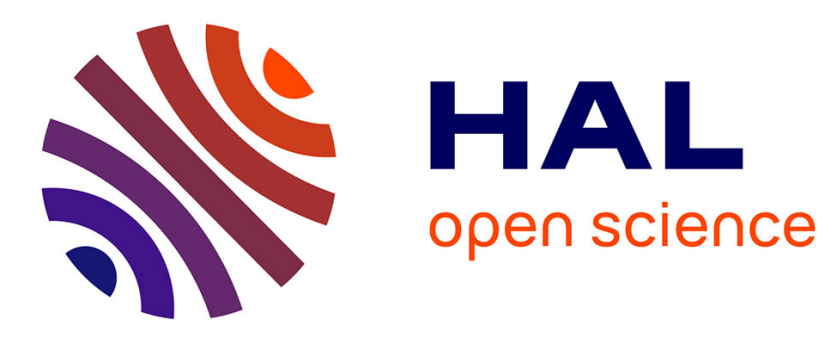

\title{
Lossless Compression of Volumetric Medical Data
}

Samy Ait-Aoudia, Fatima Zohra Benhamida, Mohamed Azzedine Yousfi

\section{To cite this version:}

Samy Ait-Aoudia, Fatima Zohra Benhamida, Mohamed Azzedine Yousfi. Lossless Compression of Volumetric Medical Data. Computer and Information Sciences - ISCIS 2006, Nov 2006, Istanbul, Turkey. pp.563-571, 10.1007/11902140_60 . hal-00849506

\section{HAL Id: hal-00849506 https://hal.science/hal-00849506}

Submitted on 31 Jul 2013

HAL is a multi-disciplinary open access archive for the deposit and dissemination of scientific research documents, whether they are published or not. The documents may come from teaching and research institutions in France or abroad, or from public or private research centers.
L'archive ouverte pluridisciplinaire HAL, est destinée au dépôt et à la diffusion de documents scientifiques de niveau recherche, publiés ou non, émanant des établissements d'enseignement et de recherche français ou étrangers, des laboratoires publics ou privés. 


\title{
Lossless Compression of Volumetric Medical Data
}

\author{
Samy Ait-Aoudia, Fatma-Zohra Benhamida, Mohamed-Azzeddine Yousfi \\ INI - Institut National d'Informatique, BP 69M, Oued-Smar 16270, Algiers, Algeria \\ s_ait_aoudia@ini.dz,
}

\begin{abstract}
Medical imaging applications produce large sets of similar images. Thus a compression technique is useful to reduce space storage. Lossless compression methods are necessary in such critical applications. Volumetric medical data presents strong similarity between successive frames. In this paper we investigate predictive techniques for lossless compression of video sequences applied to volumetric data. We also make a comparative study with other existing compression techniques dedicated to volumetric data.
\end{abstract}

\section{Introduction}

Medical imaging applications produce a huge amount of 3D data. Among these medical data we can mention CT (Computed Tomography), MR (Magnetic Resonance), PET (Position Emission Tomography) Ultrasound, X-Ray and Angiography images. Storing such amount of data need a lot of disk space. That is why compression is required in that field. In addition, medical images must be stored without any loss of information since the fidelity of images is critical in diagnosis. This requires lossless compression techniques. Lossless compression is an error free compression. The decompressed image is the same as the original image.

Classical image compression techniques (see $[1,3,4,6,7,8,10]$ ) concentrate on how to reduce the redundancies presented in an individual image. This model ignores an additional type of redundancy that exists in sets of similar images, the temporal redundancy. Volumetric $3 \mathrm{D}$ data compression techniques exploit the correlation that exists among successive image slices to achieve better compression rates.

Due to the fact that volumetric medical data presents strong similarity between successive frames, we investigate, in this paper, predictive techniques for lossless compression of video data. We also make a comparative study with other existing compression techniques dedicated to volumetric data..

This paper is organized as follows. We define in section 2, the correlation coefficient that quantify similarity between images. The predictions schemes for $3 \mathrm{D}$ data compression are explained in section 3. We briefly present in section 4 , the coding methods used for the compression. Experimental results on medical samples datasets are given in section 5. Section 6 gives conclusions. 


\section{Images similarity}

There is a strong similarity between every two successive frames in a volumetric dataset. This similarity must somehow be mathematically quantified to show the degree of resemblance. Two images are said to be similar or statistically correlated if they have similar pixel intensities in the same areas.

The correlation coefficient is used to quantify similarity. For two datasets $\mathrm{X}=\left(\mathrm{x}_{1}, \mathrm{x}_{2}, \ldots \mathrm{x}_{\mathrm{N}}\right)$ and $\mathrm{Y}=\left(\mathrm{y}_{1}, \mathrm{y}_{2}, \ldots \mathrm{y}_{\mathrm{N}}\right)$ with mean values $\mathrm{x}_{\mathrm{m}}$ and $\mathrm{y}_{\mathrm{m}}$, Neter et al. [11] defined this coefficient as :

$$
r=\frac{\sum_{i=1}^{N}\left(x_{i}-x_{m}\right)\left(y_{i}-y_{m}\right)}{\sqrt{\sum_{i=1}^{N}\left(x_{i}-x_{m}\right)^{2}} \sqrt{\sum_{i=1}^{N}\left(y_{i}-y_{m}\right)^{2}}}
$$

The correlation coefficient is also called Person's $r$. To avoid the manipulation of negative values, $r^{2}$ is often used instead of $r$. For to datasets $\mathrm{X}$ and $\mathrm{Y}$, a value of $\mathrm{r}^{2}$ close to 0 , means that no correlation exits between them. A value of $\mathrm{r}^{2}$ close to 1 , means that strong correlation exits between the two datasets. $\mathrm{X}$ and $\mathrm{Y}$ are perfectly correlated if $r^{2}=1$. In context of images, a value $r^{2}$ close to 0 means that the two images are totally dissimilar, a value $r^{2}$ close to 1 indicates "strong" similarity and a value $r^{2}=1$ means that the images are identical.
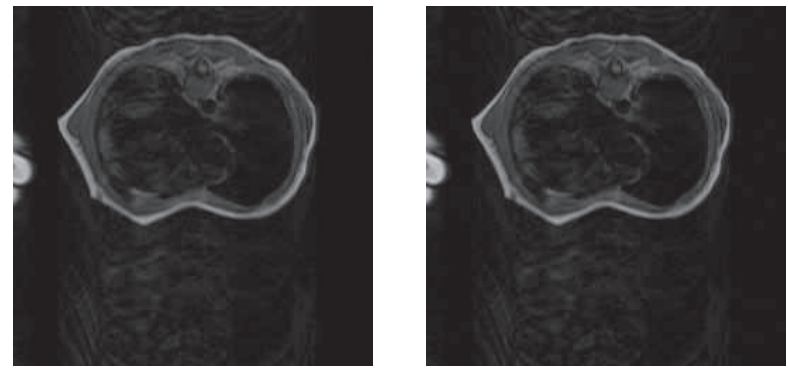

Fig.1. Two successive MR chest scans
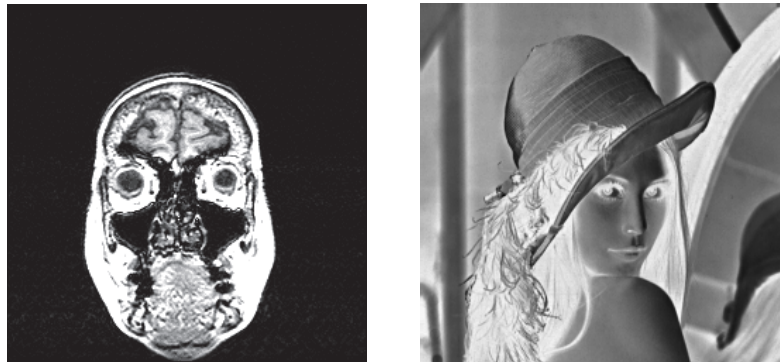

Fig.2. Two dissimilar images. 
We give two examples to quantify the similarity between images. Figure 1 shows two successive MR chest scans of a same patient. The value $r^{2}=0.997$ indicates strong similarity between these two images. Figure 2 depicts two non similar images. The correlation parameter $r^{2}=0.005$ indicates that the two images are non correlated.

\section{Prediction schemes}

A prediction model is used to predict pixel values and replace them by the error in prediction. The resulting image is called the residual image or error image. The remaining structure is then captured by a statistical or universal model prior to encoding. The first step is called decorrelation and the second step is called error modeling. The images are processed in a in raster scan order and a pixel is predicted on the basis of pixels which have already treated in the current and previous frames. In the frame $k$, we denote the current pixel $P_{k}[i, j]$ and its predicted value by $\underline{P}_{k}[i, j]$. The prediction error is then given by : $\underline{\mathrm{P}}_{k}[\mathrm{i}, \mathrm{j}]-\mathrm{P}_{\mathrm{k}}[\mathrm{i}, \mathrm{j}]$.

\subsection{DPCM}

The simplest way to extract the temporal redundancy is to subtract adjacent pixels values in two successive frames. This principle is called DPCM (Differential Pulse Code Modulation). The predicted pixel value is given by :

$$
\underline{\mathrm{P}}_{k}[\mathrm{i}, \mathrm{j}]=\mathrm{P}_{\mathrm{k}-1}[\mathrm{i}, \mathrm{j}]
$$

\subsection{D JPEG-4}

The lossless JPEG predictors are effective in removing spatial correlations present in individual frames. The JPEG standard provides eight different predictors from which the user can select. Table 1 lists the eight predictors used. Figure 3 shows the notation used for specifying neighboring pixels of the pixel being predicted.

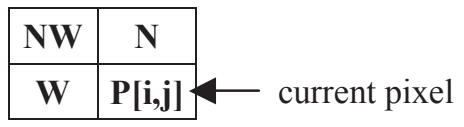

Fig.3. Notation used for specifying neighboring pixels of current pixel $\mathrm{P}[\mathrm{i}, \mathrm{j}]$. 
Table 1. JPEG predictors for lossless coding.

\begin{tabular}{cl}
\hline Mode & \multicolumn{1}{c}{ Prediction } \\
\hline 0 & 0 (no prediction) \\
1 & $\mathrm{~N}$ \\
2 & $\mathrm{~W}$ \\
3 & $\mathrm{NW}$ \\
4 & $\mathrm{~N}+\mathrm{W}-\mathrm{NW}$ \\
5 & $\mathrm{~W}+(\mathrm{N}-\mathrm{NW}) 2$ \\
6 & $\mathrm{~N}+(\mathrm{W}-\mathrm{NW}) / 2$ \\
7 & $(\mathrm{~N}+\mathrm{W}) / 2$ \\
\hline
\end{tabular}

For a video sequence or a volumetric data, using these predictors in each frame does not take into account temporal correlation. Memon et al.[9] used 3-dimensional versions of the JPEG predictors. The 3D predictors were obtained by simply taking the average of the $2 \mathrm{D}$ predictors in each of the three planes that can pass through a given pixel in three dimensions. According to Memon et al. [9] The 3D version of the predictor specified by mode 4 of lossless JPEG gave the best performance among all the $3 \mathrm{D}$ predictors. This predictor, that will be used in our experiments, is given by :

$$
\underline{\mathbf{P}}_{k}[\mathbf{i}, \mathbf{j}]=\frac{2 *\left(\mathrm{P}_{\mathrm{k}}[\mathrm{i}, \mathrm{j}-1]+\mathrm{P}_{\mathrm{k}}[\mathrm{i}-1, \mathrm{j}]_{+} \mathrm{P}_{\mathrm{k}-1}[\mathrm{i}, \mathrm{j}]\right)}{3}-\frac{\mathrm{P}_{\mathrm{k}-1}[\mathrm{i}-1, \mathrm{j}]+\mathrm{P}_{\mathrm{k}-1}[\mathrm{i}, \mathrm{j}-1]_{+} \mathrm{P}_{\mathrm{k}}[\mathrm{i}-1, \mathrm{j}-1]}{3}
$$

\subsection{D JPEG-LS}

LOCO-I (LOw COmplexity LOssless COmpression for Images) [13] uses a nonlinear predictor with edge detecting capability. The approach in LOCO-I consists on performing a test to detect edges. Specifically, the LOCO-I predictor guesses:

$$
\text { Predicted_pixel } \begin{cases}\min (\mathrm{N}, \mathrm{W}) & \text { if } \mathrm{NW} \geq \max (\mathrm{N}, \mathrm{W}) \\ \max (\mathrm{N}, \mathrm{W}) & \text { if } \mathrm{NW} \leq \min (\mathrm{N}, \mathrm{W}) \\ \mathrm{N}+\mathrm{W}-\mathrm{NW} & \text { otherwise }\end{cases}
$$

LOCO-I is the algorithm at the core of the standard compression of continuoustone images, JPEG-LS ([13]). The predictor used in LOCO-I was renamed during the standardization process "median edge detector" (MED).

From the MED predictor, we have derived and used in our experiments a 3D predictor called 3D JPEG-LS. We define it as follows:

- $\quad$ if $\left(\min \left(\mathrm{P}_{\mathrm{k}}[\mathrm{i}-1, \mathrm{j}-1], \mathrm{P}_{\mathrm{k}-1}[\mathrm{i}-1, \mathrm{j}], \mathrm{P}_{\mathrm{k}-1}[\mathrm{i}, \mathrm{j}-1]\right)>=\max \left(\mathrm{P}_{\mathrm{k}}[\mathrm{i}-1, \mathrm{j}], \mathrm{P}_{\mathrm{k}}[\mathrm{i}, \mathrm{j}-1], \mathrm{P}_{\mathrm{k}-1}[\mathrm{i}, \mathrm{j}]\right)\right)$

$$
\underline{\mathbf{P}}_{k}[i, j]=\min \left(\mathrm{P}_{\mathrm{k}}[\mathrm{i}-1, \mathrm{j}], \mathrm{P}_{\mathrm{k}}[\mathrm{i}, \mathrm{j}-1], \mathrm{P}_{\mathrm{k}-1}[\mathrm{i}, \mathrm{j}]\right)
$$

- $\quad \operatorname{if}\left(\max \left(\mathrm{P}_{\mathrm{k}}[\mathrm{i}-1, \mathrm{j}-1], \mathrm{P}_{\mathrm{k}-1}[\mathrm{i}-1, \mathrm{j}], \mathrm{P}_{\mathrm{k}-1}[\mathrm{i}, \mathrm{j}-1]\right)<=\min \left(\mathrm{P}_{\mathrm{k}}[\mathrm{i}-1, \mathrm{j}], \mathrm{P}_{\mathrm{k}}[\mathrm{i}, \mathrm{j}-1], \mathrm{P}_{\mathrm{k}-1}[\mathrm{i}, \mathrm{j}]\right)\right)$

$$
\underline{\mathbf{P}}_{k}[\mathbf{i}, \mathbf{j}]=\max \left(\mathrm{P}_{\mathrm{k}}[\mathrm{i}-1, \mathrm{j}], \mathrm{P}_{\mathrm{k}}[\mathrm{i}, \mathrm{j}-1], \mathrm{P}_{\mathrm{k}-1}[i, j]\right)
$$

- otherwise

$$
\underline{\mathbf{P}}_{\mathbf{k}}[\mathbf{i}, \mathbf{j}]=\frac{2 *\left(\mathrm{P}_{\mathrm{k}}[\mathrm{i}, \mathrm{j}-1]+\mathrm{P}_{\mathrm{k}}[\mathrm{i}-1, \mathrm{j}]_{+}+\mathrm{P}_{\mathrm{k}-1}[\mathrm{i}, \mathrm{j}]\right)}{3}-\frac{\mathrm{P}_{\mathrm{k}-1}[\mathrm{i}-1, \mathrm{j}]+\mathrm{P}_{\mathrm{k}-1}[\mathrm{i}, \mathrm{j}-1]_{+} \mathrm{P}_{\mathrm{k}}[\mathrm{i}-1, \mathrm{j}-1]}{3}
$$




\section{Encoding the residual images}

In a predictive lossless image compression technique, there are two distinct steps, decorrelation and coding. In the decorrelation step, spatial and temporal redundancies among pixels are reduced, resulting in a image called the residual image.

If the decorrelation step is effective, than the every residual image has significantly lower zero-order entropy compared to the original image slice in the $3 \mathrm{D}$ dataset. Several coding schemes were tested in the residual image encoding phase.

In our studies, we will restrict ourselves to the three techniques that gave good results. We will use arithmetic coding, PPMd and LZMA algorithms. PPMd is a PPM (Prediction by Partial Matching) based algorithm. It is a finite-context statistical modeling technique. This algorithm is mostly based on Dmitry Shkarin's work [12] The LZMA algorithm is a derivative of the Lempel-Ziv algorithm. It is an improved and optimized version of LZ77 algorithm [17].

\section{Experimental Results}

\subsection{Test Images}

The evaluation compressions methods is made on sample medical images. We present experimental results on the same CT and MR volumetric datasets used in $[2,15,16]$ for easy comparisons. All images were gray-level, and were scaled to $8 \mathrm{bits} /$ pixel. The volumetric medical data are described in table 2 . The first slice of each dataset is given in figure 4.

Table 2. Description of the datasets used in the experiments.

\begin{tabular}{llccll}
\hline Type & \multicolumn{1}{c}{ History } & Age & Sex & File name & \multicolumn{1}{c}{ Size } \\
\hline \multirow{4}{*}{ CT } & Apert's syndrom & 2 & M & Aperts & $256 \times 256 \times 96$ \\
& Internal carotid dissection & 41 & F & Carotid & $256 \times 256 \times 64$ \\
& Tripod fracture & 16 & M & Skull & $256 \times 256 \times 192$ \\
& Healing scaphoid fracture & 20 & M & Wrist & $256 \times 256 \times 176$ \\
\hline \multirow{4}{*}{ MR } & Normal & 38 & F & Liver_t1 & $256 \times 256 \times 48$ \\
& Normal & 38 & F & Liver_t2e1 & $256 \times 256 \times 48$ \\
& Congenital heart disease & 1 & M & Ped_chest & $256 \times 256 \times 64$ \\
& Left exophthalmoses & 42 & M & Sag_head & $256 \times 256 \times 48$ \\
\hline
\end{tabular}

\subsection{Compression results}

All lossless coding results are based on real compressed file sizes. In the first experiment, we have compressed the volumetric data by general purpose lossless compressors : Unix-compress, Win-Zip and Win-Rar. We also compressed the 3D data by JPEG-LS [13] the ISO/ITU standard for lossless compression of continuous 
tone-images and CALIC (Context-based Adaptive Lossless Image Coding) [14]. Lossless compression results in bit per pixel (bpp) using these compressors are given in table 3.

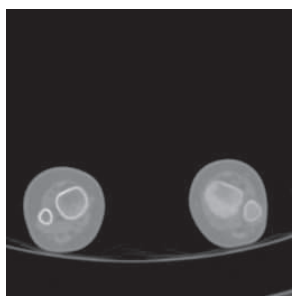

(a)

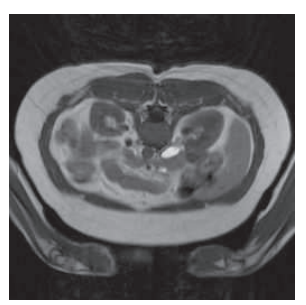

(e)

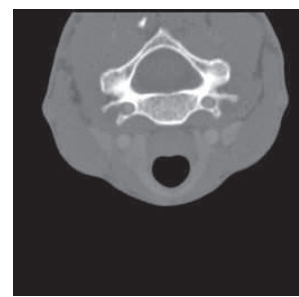

(b)

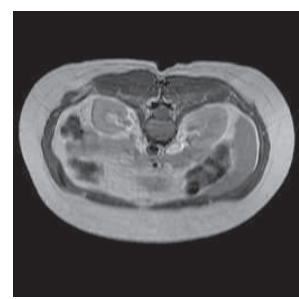

(f)

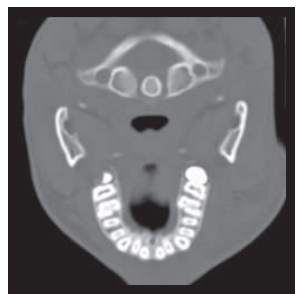

(c)

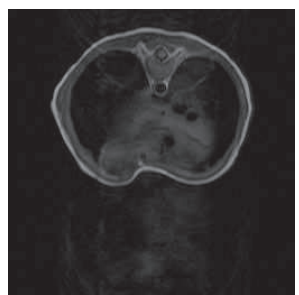

(g)

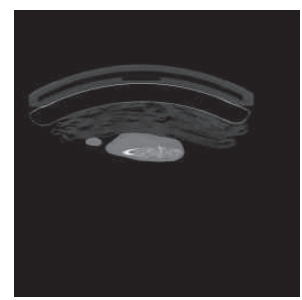

(d)

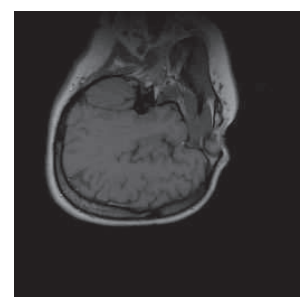

(h)

Fig.4. Volumetric medical images : First slice of each data set. (a) Aperts (b) Carotid (c) Skull (d) Wrist (e) Liver_t1 (f) Liver_t2e1 (g) Ped_chest (h) Sag_head.

Table 3. Lossless compression results in bit per pixel using standard lossless compressors.

\begin{tabular}{cccccc}
\hline \multirow{2}{*}{ Name } & $\begin{array}{c}\text { UNIX } \\
\text { Compress }\end{array}$ & $\begin{array}{c}\text { WIN } \\
\text { ZIP }\end{array}$ & $\begin{array}{c}\text { WIN } \\
\text { RAR }\end{array}$ & $\begin{array}{c}\text { JPEG } \\
\text { LS }\end{array}$ & CALIC \\
\hline Aperts & 1.739 & 1.789 & 1.494 & 1.063 & 1.047 \\
Carotid & 2.782 & 2.825 & 2.288 & 1.738 & 1.654 \\
Liver-t1 & 5.304 & 5.294 & 3.882 & 3.158 & 3.047 \\
Liver-t2 & 3.938 & 3.738 & 3.033 & 2.369 & 2.243 \\
Ped-Chest & 4.333 & 4.509 & 3.796 & 2.928 & 2.810 \\
Sag-Head & 3.595 & 3.569 & 3.323 & 2.556 & 2.585 \\
Skull & 4.135 & 3.944 & 3.741 & 2.846 & 2.725 \\
Wrist & 2.720 & 2.801 & 1.901 & 1.653 & 1.691 \\
\hline
\end{tabular}

In the second experiment, we have compressed the volumetric data by first decorrelating these data and then coding them. The decorrelation phase was made by using the three predictors DPCM, 3D JPEG-3 and 3D JPEG-LS. In the coding phase we have used several techniques. In our experiments three methods gave good results. These methods are : arithmetic coding, LZMA algorithm and PPMd algorithm.

Table 4, table 5 and table 6 give lossless compression results in bit per pixel (bpp) when using for the coding step arithmetic coding, LZMA algorithm and PPMd algorithm respectively. 
Table 4. Arithmetic lossless compression results in bit per pixel.

\begin{tabular}{cccc}
\hline Name & $\begin{array}{c}\text { DPCM } \\
\text { Arithmetic }\end{array}$ & $\begin{array}{c}\text { 3D JPEG-4 } \\
\text { Arithmetic }\end{array}$ & $\begin{array}{c}\text { LS-3D } \\
\text { Arithmetic }\end{array}$ \\
\hline Aperts & 1.192 & 1.238 & 1.330 \\
Carotid & 1.940 & 1.965 & 2.083 \\
Liver-t1 & 2.941 & 3.125 & 3.330 \\
Liver-t2 & 2.555 & 2.622 & 2.675 \\
Ped-Chest & 1.839 & 2.768 & 3.112 \\
Sag-Head & 2.453 & 2.758 & 2.898 \\
Skull & 2.631 & 3.112 & 3.174 \\
Wrist & 1.384 & 1.652 & 1.818 \\
\hline
\end{tabular}

Table 5. LZMA lossless compression results in bit per pixel.

\begin{tabular}{cccc}
\hline Name & $\begin{array}{c}\text { DPCM } \\
\text { LZMA }\end{array}$ & $\begin{array}{c}\text { 3D JPEG-4 } \\
\text { LZMA }\end{array}$ & $\begin{array}{c}\text { LS-3D } \\
\text { LZMA }\end{array}$ \\
\hline Aperts & 1.062 & 1.199 & 1.236 \\
Carotid & 1.733 & 1.859 & 1.995 \\
Liver-t1 & 2.722 & 3.290 & 3.483 \\
Liver-t2 & 1.905 & 2.478 & 2.500 \\
Ped-Chest & 1.757 & 2.853 & 3.053 \\
Sag-Head & 2.232 & 2.752 & 2.809 \\
Skull & 2.182 & 2.972 & 3.102 \\
Wrist & 1.151 & 1.555 & 1.713 \\
\hline
\end{tabular}

Table 6. PPMd lossless compression results in bit per pixel.

\begin{tabular}{cccc}
\hline Name & $\begin{array}{c}\text { DPCM } \\
\text { PPMD }\end{array}$ & $\begin{array}{c}\text { 3D JPEG-4 } \\
\text { PPMD }\end{array}$ & $\begin{array}{c}\text { LS-3D } \\
\text { PPMD }\end{array}$ \\
\hline Aperts & 0.867 & 1.004 & 1.119 \\
Carotid & 1.471 & 1.625 & 1.817 \\
Liver-t1 & 2.390 & 3.039 & 3.320 \\
Liver-t2 & 2.025 & 2.406 & 2.509 \\
Ped-Chest & 1.689 & 2.687 & 3.112 \\
Sag-Head & 2.127 & 2.619 & 2.747 \\
Skull & 2.119 & 2.716 & 2.928 \\
Wrist & 1.029 & 1.372 & 1.569 \\
\hline
\end{tabular}


We have finally compared the results obtained with relatively recent volumetric data compression that uses wavelets. In table 7, the columns '3D SPIHT' and '3D ATSPIHT' refer to the results with lossless variations of 3D SPIHT [5]. The columns '3D ESCOT' and '3D CB-EZW' refer to the lossless results with 3D ESCOT [15] and 3D CB-EZW [2]. The column '3-D NL $(\delta=0)$ ' refers to the 3D wavelet based two-stage lossless coder described in [16]. All these results can be found in [16]. The last column refers to DPCM-PPMd the best predictive technique in the tests conducted. Boldface entry in each column indicates the best result for the corresponding dataset.

Table 7. Bits rates for lossless compression, average bitrate in bits per pixel (bpp).

\begin{tabular}{ccccccc}
\hline \multirow{2}{*}{ Name } & $\begin{array}{c}\text { 3D } \\
\text { SPIHT }\end{array}$ & $\begin{array}{c}\text { 3D AT- } \\
\text { SPIHT }\end{array}$ & $\begin{array}{c}\text { 3D } \\
\text { ESCOT }\end{array}$ & $\begin{array}{c}\text { 3D CB- } \\
\text { EZW }\end{array}$ & $\begin{array}{c}\text { 3-D NL } \\
(\boldsymbol{\delta}=\mathbf{0})\end{array}$ & $\begin{array}{c}\text { DPCM } \\
\text { PPMD }\end{array}$ \\
\hline Aperts & 1.054 & 1.039 & 0.9 & 1.013 & 0.933 & $\mathbf{0 . 8 6 7}$ \\
Carotid & 1.497 & 1.497 & $\mathbf{1 . 4}$ & 1.455 & 1.650 & 1.471 \\
Liver-t1 & 2.399 & 2.369 & $\mathbf{2 . 2}$ & 2.415 & 2.376 & 2.390 \\
Liver-t2 & 1.748 & 1.744 & $\mathbf{1 . 6}$ & 1.753 & 1.856 & 2.025 \\
Ped-Chest & 2.104 & 2.054 & 1.9 & 2.117 & 1.770 & $\mathbf{1 . 6 8 9}$ \\
Sag-Head & 2.240 & 2.202 & $\mathbf{2 . 0}$ & 2.356 & 2.136 & 2.127 \\
Skull & 2.113 & 2.166 & $\mathbf{2 . 0}$ & 2.204 & 2.405 & 2.119 \\
Wrist & 1.368 & 1.355 & 1.2 & 1.327 & 1.144 & $\mathbf{1 . 0 2 9}$ \\
\hline
\end{tabular}

\subsection{Discussion}

From the results shown in previous tables, we see that most of the $3 \mathrm{D}$ compressions methods carry out an improvement compared to individual image standard compression. From table 7, we see that the DPCM-PPMd method performed the best for three of eight test sequences. This can be explained by the fact that high similarity is present in the three sequences (CT_Aperts, MR_Ped-Chest and CT_Wrist). The correlation coefficient for every two successive slices in each of these datasets is always superior to 0.99 . When the correlation coefficient decreases (as this is the case for MR_Liver-t2 sequence) the DPCM-PPMD will not be effective.

\section{Conclusion}

One of the best application areas for volumetric compression methods is medical imaging. Medical image databases usually store huge amount of similar images. This paper attempts to evaluate the performance of lossless volumetric compression on sample datasets of grayscale similar images. In this study, only the effect of compressing sets of grayscale images was evaluated. Further works must consider compressing sets true color images. Spectral decorrelation must then be taken into 
account. 3D compression methods can also be tested on many other application areas. Satellite image databases, for example, often contain sets of images taken over the same geographical areas, and under similar weather or lighting conditions. They necessarily contain inter-image redundancy.

\section{References}

[1] Bekkouche H. and Barret M., Adaptive multiresolution decomposition: application to lossless image compression, ICASSP 2002, Orlando Florida, USA, May 2002.

[2] Bilgin A., Zweig G., and Marcellin M.W., Three-Dimensional Image Compression with Integer Wavelet Applied Optics, vol.39, n¹1, pp. 1799-1814, April 2000.

[3] Celik M.U., Sharma G., and Tekalp A.M., Gray-level embedded lossless image compression, ICASSP 2003, 6-10 April 2003, Honk-Kong, pp. III_245-248.

[4] Chang C.C. and Chen G.I, Enhancement algorithm for nonlinear context-based predictors, IEE Proc.-Vis Image Signal Processing, vol. 150, n 1, February 2003.

[5] Cho S., Kim D. and Pearlman W.A, Lossless Compression of Volumetric Medical Images with Improved Three-Dimensional SPIHT Algorithm, Journal of Digital Imaging, vol.17, $\mathrm{n}^{\circ} 1$, pp. 57-63, March 2004.

[6] Clunie D., Lossless compression of grayscale medical images and Effectiveness of traditional and state of the art approaches, in Proc. SPIE-Medical Imaging, Vol. 3980, 2000

[7] Falkowski B.J., Compact representations of logic functions forlossless compression of grey-scale images, IEE Proc.-Comput. Digit. Tech., Vol. 151, No. 3, May 2004, pp 221230.

[8] Jiang J., Guo B. and Yang S.Y., Revisiting the JPEG-LS prediction scheme, IEE Proc.Vis Image Signal Processing, vol. 147, $n^{\circ}$ 6, Decembre 2000.

[9] Memon N.D., and Sayood K., Lossless Compression of Video Sequences, IEEE trans. On Communications, 44(10), pp.1340-1345, Oct.1996.

[10] Memon N.D., and Wu X., Recent Developments in Context-Based Predictive Techniques for Lossless Image Compression, The Computer Journal, Vol.40(2/3), pp.127-136, 1997.

[11] Neter, J., Wasserman W., and Kutner M.H., Applied Linear Regression Models, IRWIN Burr Rigde, IL, 1989.

[12] Shkarin, D., Improving the efficiency of PPM algorithm, Problems of Information Transmission, Volume 37, Number 3, July 2001, pp. 226-235(10).

[13] Weinberger M. J., Seroussi G., and Sapiro G., The LOCO-I Lossless Image Compression Algorithm: Principles and Standardization into JPEG-LS, IEEE Transactions on Image Processing, Vol. 9, N. 8, August 2000, pp. 1309-1324.

[14] Wu X. and Memon N., Context-based, adaptive, lossless image codec" IEEE Trans. Commun., vol. 45 (4), Apr. 1997, pp. 437-444.

[15] Xiong Z., Wu X., Cheng S. and Hua J., Lossy to Lossless Compression of Medical Volumetric Data Using Three-Dimensional Integer Wavelet Transforms, IEEE trans. On Medical Imaging, vol. 22, n³, pp. 459-470, March 2003.

[16] Yea S., Cho S. and Pearlman W.A., Integrated Lossy, Near-lossless, and Lossless Compression of Medical Volumetric Data, ,Image and Video Communications and Processing 2005, IS\&T/SPIE Symposium on Electronic Imaging, 2005, Proc. SPIE 5685, Vol. 2, pp. 151-159, Jan. 2005.

[17] Ziv J., and A. Lempel, A universal algorithm for sequential data compression, IEEE Trans. Inf. Theory, vol. IT-23, no. 3, pp. 337-343, May 1977. 